\title{
Exfoliative cytology of diffuse mesothelioma
}

\author{
G. HEFIN ROBERTS AND G. M. CAMPBELL
}

From the Pathology Department, Southern General Hospital, Glasgow

SYNOPSIS The exfoliative cytology of 14 diffuse mesothelioma (11 pleural and three peritoneal) is described. Malignant cells were identified in 10 patients; in eight malignant cells still retaining the characteristics of mesothelial cells were found. It is suggested that only if malignant cells of this type are recognized should the probable diagnosis of diffuse mesothelioma be made.

The present consensus of opinion is that diagnosis of diffuse mesothelioma of the pleura and peritoneum by cytological examination of the pleural or ascitic fluid is difficult (Naylor, 1963; Koss, 1968). The Working Group on Asbestos and Cancer (International Union against Cancer, 1965) was of the opinion that only in a few cases was it possible to be confident of the diagnosis from cytology alone.

Cytology can, however, be a guide to possible cases of mesothelioma (McCaughey, 1965) as it enables a provisional diagnosis to be suggested, to be confirmed by biopsy if possible (Ratzer, Pool, and Melamed, 1968). Klempman (1962) said that malignant mesothelioma could be identified with reasonable certainty.

In this paper the cytology of the pleural fluid in 11 patients with diffuse pleural mesothelioma and the ascitic fluid in three patients with peritoneal mesothelioma will be described. Histological confirmation was available in all.

\section{Patients and Methods}

Cases 1-8 inclusive are from a larger series of 20 diffuse pleural mesothelioma seen at the Southern General Hospital, Glasgow, during the 18 years 1950-67, in which the pleural fluid was examined. Cases 9, 10, and 11 are from a series of four peritoneal mesothelioma seen at the same hospital in the last four years. The clinical details, morbid anatomy, histology, and relation to asbestos exposure of these 24 cases have previously been described (Roberts, 1970; Roberts and Irvine, 1970). The last three examples of pleural mesothelioma (cases 12,13,14) have been seen within the last two years, two patients (cases $12,14)$ are still alive. Case 13 was diagnosed at necropsy. The Table summarizes the findings.

In the first eight cases the smears prepared from the Received for publication 17 February 1972.

\begin{tabular}{|c|c|c|c|c|c|c|}
\hline $\begin{array}{l}\text { Case } \\
\text { No. }\end{array}$ & Sex & $\begin{array}{l}\text { Age } \\
(y r)\end{array}$ & Site & Diagnosis & Histology & Cytology \\
\hline 1 & $\mathbf{M}$ & 28 & Pleura & Necropsy & Epithelial & + \\
\hline 2 & $\mathbf{M}$ & 78 & Pleura & Necropsy & Mesenchymal & $1-$ \\
\hline 3 & $\mathbf{F}$ & 69 & Pleura & Necropsy & Epithelial & + \\
\hline 4 & $\mathbf{F}$ & 76 & Pleura & Necropsy & Epithelial & + \\
\hline 5 & $\mathbf{M}$ & 55 & Pleura & Necropsy & Epithelial & - \\
\hline 6 & $\mathbf{M}$ & 57 & Pleura & Necropsy & Epithelial & + \\
\hline 7 & $\mathbf{M}$ & 53 & Pleura & Necropsy & Mesenchymal & $1-$ \\
\hline 8 & $\mathbf{M}$ & 59 & Pleura & Necropsy & Epithelial & + \\
\hline 9 & $\mathbf{M}$ & 59 & Peritoneal & Necropsy & Epithelial & + \\
\hline 10 & $\mathbf{F}$ & 67 & Peritoneal & $\begin{array}{l}\text { Biopsy } \\
\text { Necropsy }\end{array}$ & Epithelial & + \\
\hline 11 & $\mathbf{F}$ & 59 & Peritoneal & Biopsy & Epithelial & + \\
\hline 12 & $\mathbf{M}$ & 66 & Pleura & Biopsy & Epithelial & - \\
\hline 13 & $\mathbf{M}$ & 75 & Pleura & Necropsy & Mixed & + \\
\hline 14 & $\mathbf{M}$ & 60 & Pleura & Biopsy & Epithelial & + \\
\hline
\end{tabular}

Table Summary of findings in 14 diffuse mesothelioma

centrifuged deposit of the fluids were air dried, fixed in $3 \%$ acetic-alcohol, and stained with haematoxylin and eosin and by the Papanicolaou method. Pleural and peritoneal fluids from the last six patients were processed by a Millipore filter technique. The centrifuged deposits were washed in $0.5 \%$ acetic acid to remove red blood cells, resuspended in normal saline, and passed through a $13 \mathrm{~mm}$ Millipore filter ( $5 \mu$ pore size), using a Swinnex-13 filtration system. The filters were then fixed in $3 \%$ aceticalcohol for 30 minutes and stained with haematoxylin and eosin.

Special stains, such as the periodic acid Schiff technique, were not used routinely.

As the histology of pleural and peritoneal mesothelioma is essentially similar, they were placed in one of three groups, namely, epithelial, mesenchymal, or 'mixed' (McCaughey, 1958).

\section{Results}

In two patients with peritoneal mesothelioma 
(cases 9, 11) and one with pleural mesothelioma (case 14) the initial diagnosis of probable mesothelioma was suggested on the presence of malignant cells of recognizable mesothelial cell type. These three cases have been seen within the last four years. On reviewing earlier cases, malignant cells of a similar type were identified in a further four patients with pleural mesothelioma (cases $1,3,6,8$ ) and in one with peritoneal mesothelioma (case 10).

The smears from these eight cases were amongst the most cellular seen (Fig. 1) and contained numerous red blood cells. This was better appreciated in the earlier cases using air-dried smears.

Malignant cells were arranged in tight clusters $\overrightarrow{\vec{D}}$ (Figs. 1, 2) or in looser, mosaic-like aggregations of $\overline{0}$ varying size (Fig. 3). The clusters showed either a round or smooth, knobbly outline (Fig. 2). Nuclei tended to have a central position, but some clusters showed a peripheral rim of flattened cells. True acinar structures with a central lumen were not seen.

Where aggregations of malignant cells were present, articulations of a type sometimes seen in benign

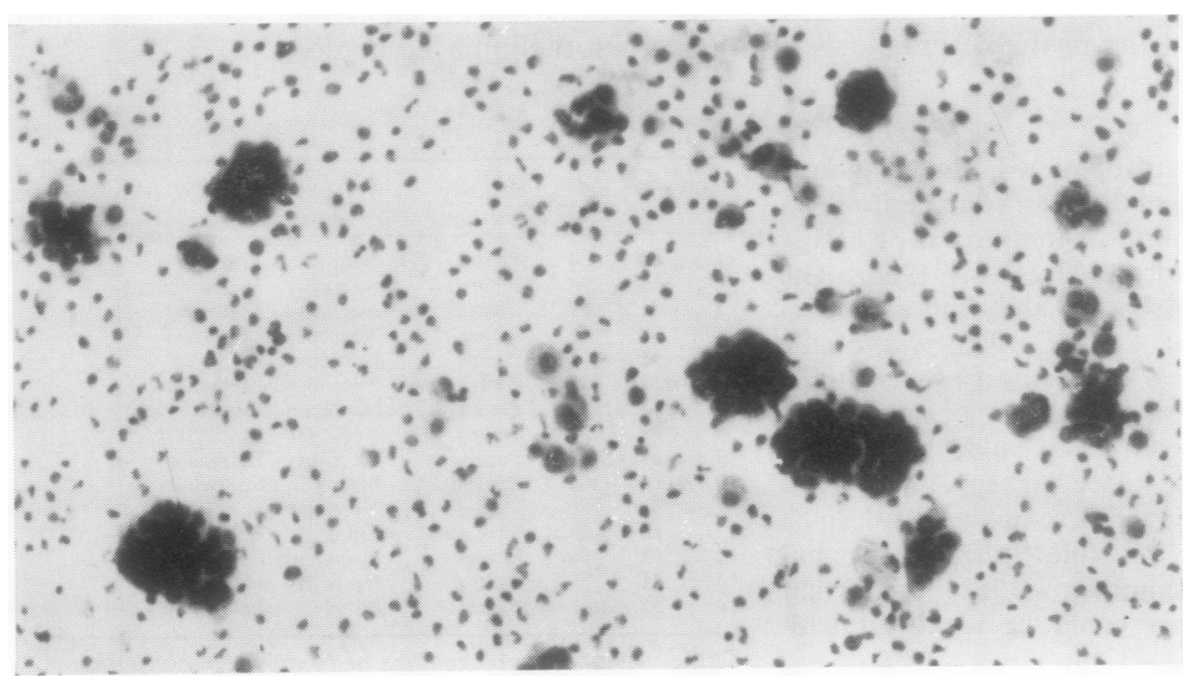

Fig. 1.

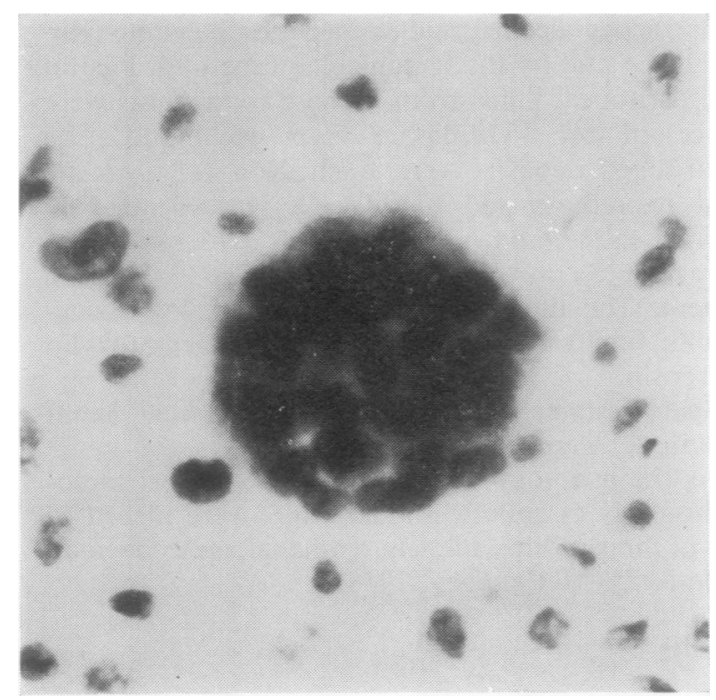

Fig. 1 Case 14. Pleural mesothelioma. Cellular smears showing solid clusters of malignant cells $(H E \times 200$; Millipore technique).

Fig. 2 Case 14. Pleural mesothelioma. Cluster of malignant mesothelial cells with smooth, knobbly outline (HE $\times$ 800; Millipore technique).

Fig. 2. 


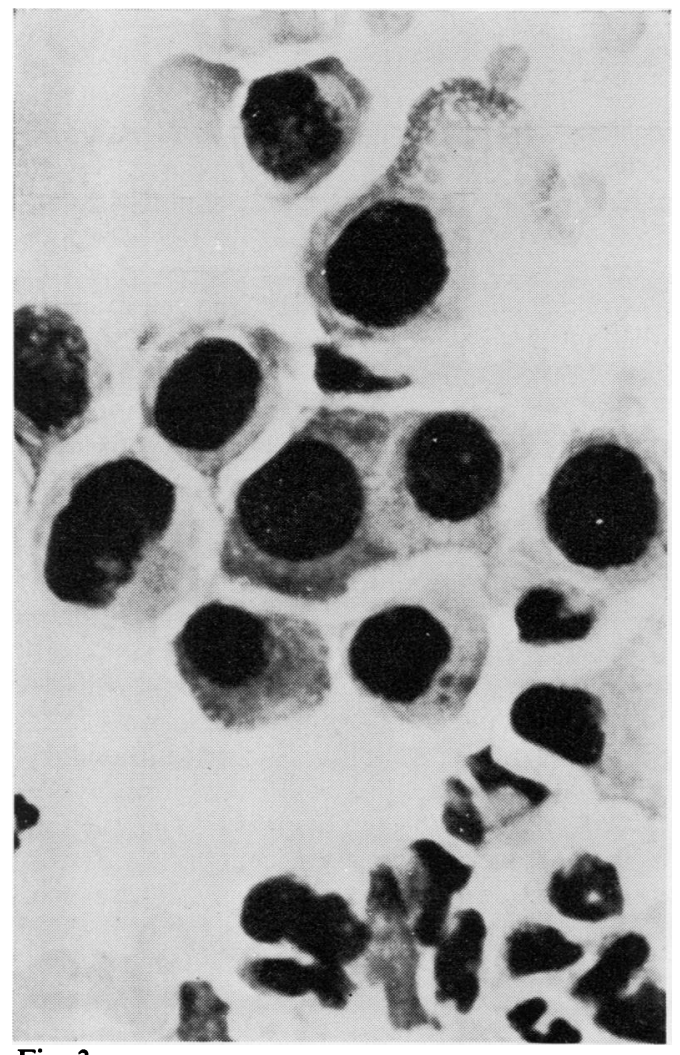

Fig. 3.

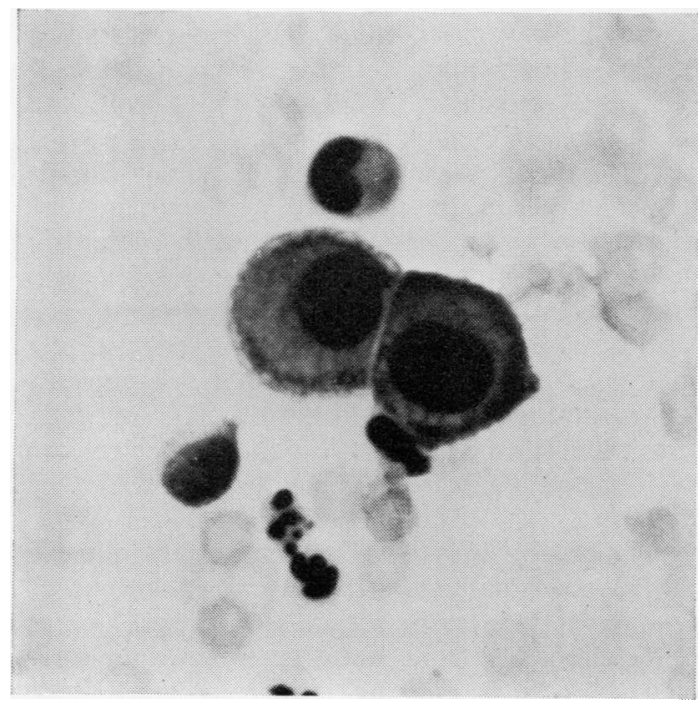

Fig. 4.

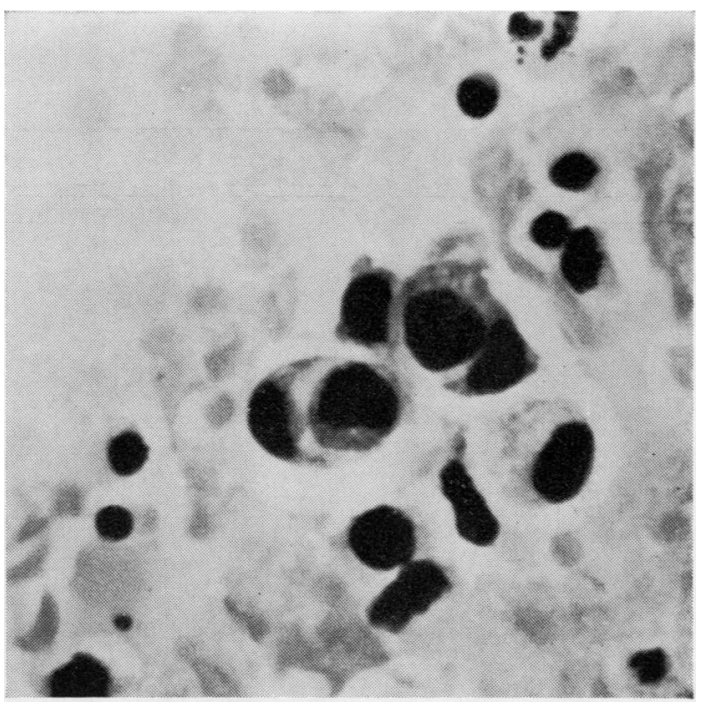

Fig. 5.

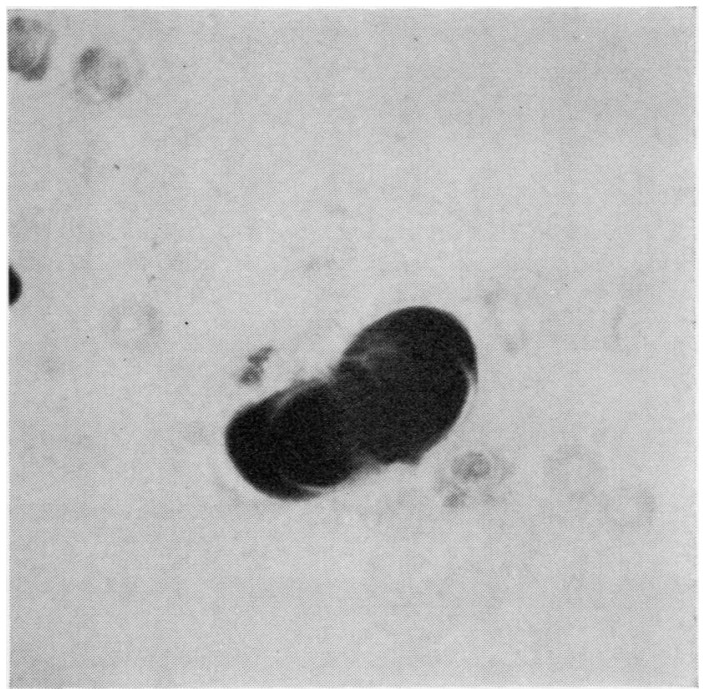

Fig. 6.

Fig. 3 Case 3. Pleural mesothelioma. Mosaic aggregation of malignant mesothelial cells $(H E \times 800$, air-dried smear).

Fig. 4 Case 3. Pleural mesothelioma. Malignant mesothelial cells showing flat apposed surfaces (HE $\times$ 800; air-dried smear).

Fig. 5 Case 9. Peritoneal mesothelioma. 'Pincer-like' articulation between two malignant mesothelial cells (HE $\times$ 800; Millipore technique).

Fig. 6 Case 9. Peritoneal mesothelioma. Malignant mesothelial cells showing cannibalism (HE $\times 800$; Millipore technique). 


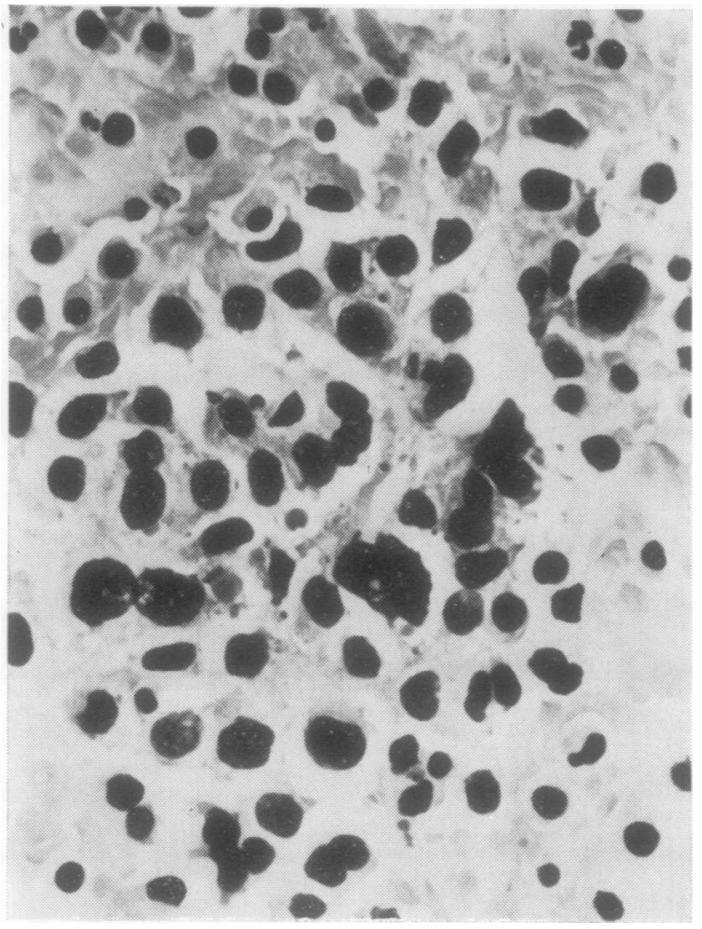

Fig. 7. Case 4. Pleural mesothelioma. Cellular smears showing malignant cells with anisocytosis and dense hyperchromatic nuclei $(H E \times 400$; air-dried smear $)$.

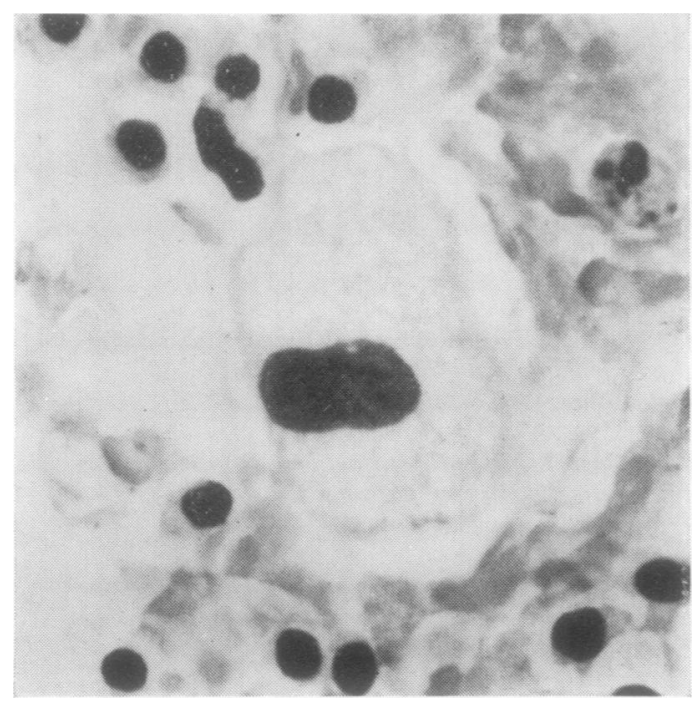

Fig. 8 Case 4. Pleural mesothelioma. Large vacuolated malignant cells $(H E \times 800 ;$ air-dried smear $)$. mesothelial cells were found. Flattening of the apposed cell boundaries, either between two or more cells, was prominent (Fig. 4), also 'pincer-like articulations' and cannibalism of one malignant cell by another (Figs. 5, 6). Single malignant cells were invariably present. These varied only slightly in size, and although tumour giant cells with one or more nuclei could be found, the majority were of a size similar to normal mesothelial cells. The cell margins were distinct and intact. The cytoplasm varied considerably in amount, and was optically dense and 'hard' and stained eosinophilic or amphophilic. Fine vacuolization towards the periphery of cells was seen in five of the eight cases, most prominently in cells with eccentric nuclei.

In all eight cases, numerous mesothelial cells with none of the usually accepted criteria of malignancy were found. Some were normal size, others were hypertrophied; the nuclei were 'atypical' but showed less abnormality than the frankly malignant cells.

In the pleural fluid from two patients (cases 4,13 ), malignant cells of a type not usually seen in secondary carcinoma were seen, but no characteristics of mesothelial cells could be identified. The pleural smears from both patients were cellular. In case 4 virtually all the cells were malignant. There was marked anisocytosis with numerous tumour giant cells; other cells were smaller than normal mesothelial cells. The nuclei were dense and hyperchromatic (Fig. 7), the cytoplasm was scanty, eosinophilic and opaque, a few cells showed fine or coarse vacuolization (Fig. 8). Tight clusters of malignant cells were not present but there was the occasional loose aggregate of malignant cells. These did not show the articulations between cells that were seen in the first group of eight cases. In case 13 malignant cells were less numerous, but of a similar type. In addition some coarsely vacuolated mesothelial cells were present; these did not show the usual features of malignant cells.

In two patients (cases 5,12 ) the cellular bloodstained pleural smears consisted predominantly of large, coarsely vacuolated cells with eccentric nuclei, some compressed against the cell margin, giving a 'signet ring' appearance. Also present were moderate numbers of mesothelial cells found singly or in small clusters. The majority had one nucleus, a few showed up to three. Definite malignant cells were not identified in these two patients; the smears were reported as being 'suspicious of secondary carcinoma'.

No malignant cells were present in the pleural fluids from two patients in whom mesothelioma of mesenchymal type were found at necropsy (cases $2,7)$. The smears from both were heavily bloodstained, in case 2 showing numerous small dark 
lymphocytes with an occasional 'atypical' mesothelial cell. In case 7 the smears consisted entirely of red blood cells, but no further comment was possible.

\section{Discussion}

The cytological diagnosis of diffuse mesothelioma depends on the identification of malignant cells which still retain the characteristics of mesothelial cells (Klempman, 1962). The diagnosis also requires familiarity with the wide range of appearances seen in benign mesothelial cells (Graham, 1963; Naylor, 1963 ; Koss, 1968).

In the present series, the pleural or ascitic fluid from eight patients showed malignant cells with characteristics of mesothelial cells. Four of these have been seen during the last four years, in three the diagnosis of mesothelioma was initially suggested on the basis of the cytological findings.

Features which enabled a mesothelial cell origin to be suggested were seen both in individual malignant cells and also in the arrangement of the cells. Individual cells showed a distinct, intact border, optically dense cytoplasm, which in haematoxylinand-eosin-stained preparations stained eosinophilic or amphophilic; some cells showed fine peripheral vacuolization. The size of the majority of cells did not differ greatly from that of normal mesothelial cells. Klempman (1962) defined such cells with intact borders as differentiated malignant mesothelial cells, and said that the diagnosis of diffuse mesothelioma depended on the identification of such cells. The nuclei showed the usually accepted criteria of malignancy.

The types of cellular articulation seen in these eight cases are all characteristic of the mesothelial cell, and, according to Naylor (1963), are not seen in any other cell encountered in serous fluids. These include flattening of apposed surfaces, pincer-like articulations, and cannibalism. In addition there were solid clusters of malignant cells with either smooth or knobbly outlines and central nuclei; some clusters showed a peripheral layer of flattened cells. It was easizr to be certain that these were malignant than to be confident that they were of mesothelial origin, although Klempman (1962) said that clusters of malignant cells in secondary carcinoma have peripheral nuclei. In none of these eight cases did the effusions show identifiable glandular structures with a central lumen. Koss (1968) mentions such an acinar pattern as a feature of secondary adenocarcinoma; Klempman (1962), however, illustrates a 'malignant acinus' in a histologically proven pleural mesothelioma. But caution is needed in interpreting acinar structures as being diagnostic of malignant effusions. Luse and Reagan
(1954) studied sections of the centrifuged deposit of 396 effusions not associated with malignant tumours in which the aetiology was known. Acinar structures were found in 23 specimens $(6 \%)$ and were present most often in effusions due to congestive cardiac failure and cirrhosis. Luse and Reagan stress that it is not always possible to differentiate with certainty the acinar-like structures in benign effusions from those seen in adenocarcinoma.

In two patients with pleural mesothelioma (cases 4 and 13) malignant cells which did not show characteristics of differentiated mesothelial cells were identified. The malignant cells showed more anisocytosis than in the first group of eight cases; tumour giant cells were frequent. The cytoplasm was scanty and the nuclei were dense and hyperchromatic. The articulations and characteristic grouping seen in the first eight cases were absent. The appearances were not those usually associated with secondary adenocarcinoma (Graham, 1963; Koss, 1968). The dense hyperchromatic nuclei and opaque cytoplasm were reminiscent of malignant squamous cells which are occasionally seen in malignant effusions (Hughes and Dodds, 1968). In Klempman's study (1962) of the exfoliative cytology of 27 pleural mesothelioma, two cases were described in which only undifferentiated malignant cells were identified. Although metastatic tumours can present with a similar pattern, Klempman suggested that the possibility of mesothelioma should be considered and that a careful search should be made for differentiated malignant mesothelial cells.

No malignant cells were identified in the remaining four cases. In two (cases 5,12 ) the smears consisted predominantly of coarsely vacuolated cells, some showing a signet ring appearance. These are probably degenerate mesothelial cells (Spriggs and Boddington, 1968) and unrelated to the type of malignant tumour present (Koss, 1968). Luse and Reagan (1954) found signet-ring forms in 152 of $396(38 \%)$ of effusions not associated with malignant tumours. Naylor (1963) also commented on and illustrated coarsely vacuolated cells in his series of seven diffuse mesothelioma; he concluded that they were of mesothelial origin. In Klempman's series of 27 cases 'balloon vacuoles' in the cytoplasm were seen only in one case. This coarse vacuolization must be distinguished from the fine, peripheral vacuoles noted in the first group of eight cases; in these the cells were of recognizablemesothelial origin.

In the remaining two patients with 'negative malignant cytology' (cases 2,7 ) the pleural smears in one (case 7) consisted only of red blood cells. The other showed numerous red blood cells with small lymphocytes and a few 'atypical' mesothelial cells. The histology of both these pleural tumours showed 
mesothelioma of mesenchymal (sarcomatous) pattern (McCaughey, 1958). Koss (1968) says that in such 'fibrosarcomatous mesothelioma' there is none of the diagnostic difficulty which is encountered with tumours of the epithelial type. The malignant cells are spindly and often form whorls; Ratzer et al (1969) saw such cells in six of nine patients with mesothelioma of mesenchymal pattern. Klempman (1962) identified sheets of spindle cells in two cases but did not give details of the histolcgy.

Malignant mesothelioma is an exception to the general rule that in malignant effusions there is a recognizable dissimilarity of two cell populations, viz, malignant cells and mesothelial cells. In malignant mesothelioma, tumour cells and benign mesothelial cells may not show a clear dividing line (Spriggs and Boddington, 1968). The smears from 13 cases showed moderate or numerous mesothelial cells, some of which appeared morphologically benign and others were 'atypical'. These atypical cells were either of normal size or hypertrophied; the nuclei, although abnormal, did not show the usually accepted criteria of malignant cells.

The interpretation and diagnostic value of such 'normal' and atypical mesothelial cells is uncertain. Malignant mesothelial cells may resemble benign mesothelial cells (Koss, 1968) and conversely mesothelial cell hyperplasia and hypertrophy can easily be mistaken for malignant mesothelioma (Naylor, 1963). In all Naylor's seven cases there were cells of a type that could not be readily diagnosed as malignant. Even in cells that were thought to be malignant, the nuclear abnormalities were not as marked as in exfoliated cells from squamous carcinoma or adenocarcinoma. Klempman (1962) also stressed that mesothelial cell atypicality could be such that it was impossible to decide whether or not the cells were malignant. In addition to these difficulties of distinguishing a benign or atypical mesothelial cell from a malignant mesothelial cell it is also well recognized that mesothelial cells can show a wide range of changes in a variety of benign diseases and as a result of degeneration (Graham, 1963; Hughes and Dodds, 1968; Koss, 1968). We are of the opinion that the diagnostic value of atypical mesothelial cells as an aid to the diagnosis of mesothelioma is limited. If an unacceptable number of 'false positive' reports is to be avoided, we suggest that a 'probable' diagnosis of mesothelioma be suggested only in cases where cells whose nuclei show the usually accepted criteria of malignant cells are present and where the other characteristics of mesothelial cells as discussed can also be identified. The first group of eight cases in the present series appears to fulfil these criteria.

Thanks are due to Dr A. Dick for helpful criticism and to Mr G. F. Headden for the photomicrography.

\section{References}

Graham, R. M. (1963). The Cytologic Diagnosis of Cancer, 2nd ed., p. 289. Saunders, Philadelphia.

Hughes, H. E., and Dodds, T. C. (1968). Handbook of Diagnostic Cytology, p. 159. Livingstone, Edinburgh.

International Union against Cancer (1965). Report and recommendations of Working Group on asbestos and cancer convened under the auspices of the Geographical Pathology Section of the International Union Against Cancer. Ann. N.Y. Acad. Sci., 132, 706-721.

Klempman, S. (1962). The exfoliative cytology of diffuse pleura mesothelioma. Cancer (Philad.), 15, 691-703.

Koss, L. G. (1968). Diagnostic Cytology and its Histopathologic Bases, 2nd ed., p. 505. Lippincott, Philadelphia.

Luse, S. A., and Reagan, J. W. (1954). A histocytological study of effusions. 7. Effusions not associated with malignant tumours. Cancer (Philad.), 7, 1155-1166.

McCaughey, W. T. E. (1958). Primary tumours of the pleura.J. Path Bact., 76, 517-529.

McCaughey, W. T. E. (1965). Criteria for diagnosis of diffuse mesothelial tumours. Ann. N.Y. Acad. Sci., 132, 603-613.

Naylor, B. (1963). The exfoliative cytology of diffuse malignan mesothelioma. J. Path. Bact., 86, 293-298.

Ratzer, E. R., Pool, J. L., and Melamed, M. R. (1967). Pleural mesotheliomas: clinical experience with thirty-seven patients. Amer. J. Roentgenol., 99, 863-880.

Roberts, G. H. (1970). Diffuse pleural mesothelioma: a clinical an pathological study. Brit. J. Dis. Chest., 64, 201-211.

Roberts, G. H., and Irvine, R. W. (1970). Peritoneal mesothelioma a report of 4 cases. Brit. J. Surg., 57, 645-650.

Spriggs, A. I. and Boddington, M. M. (1968). The Cytology of Effusions, 2nd ed., 6, pp. 23, 31. Heinemann, London. 